Agro-Science Journal of Tropical Agriculture, Food, Environment and Extension Volume 20 Number 2 (April 2021) pp. 20 - 24

ISSN 1119-7455

\title{
GENOTYPE $\times$ ENVIRONMENT ANALYSIS OF COWPEA GRAIN PRODUCTION IN THE FOREST AND DERIVED SAVANNAH CULTIVATION ECOLOGIES
}

\author{
"Nassir A.L., Olayiwola M.O., Olagunju S.O., Adewusi K.M. and Jinadu S.S. \\ Department of Crop Production, Faculty of Agricultural Production \& Renewable Resources, \\ College of Agricultural Sciences, Olabisi Onabanjo University, Ago-Iwoye, Ogun State, Nigeria \\ *Corresponding author's email: adesola.nassir@oouagoiwoye.edu.ng; adesolanassir@gmail.com
}

\begin{abstract}
Differential performance of genotypes in different cultivation environments has remained a challenge to farmers and plant breeders, the emphasis being the selection of high yielding and stable genotypes, across similar ecologies. A set of nine cowpea genotypes were cultivated in Ago-Iwoye and Ayetoro, two locations representing high and moderate moisture zones. Plantings were done with the early and late season rains in Ago-Iwoye and mid-late season rains of Ayetoro. Statistical analysis was done to understand genotype reaction to the different environments and the plant and environment factors mediating the performance. The Additive Main Effect and Multiplicative Interaction (AMMI) model captured 61.30\% of the total sum of squares (TSS). The main effects: genotype (G) environment (E) and their interaction (GxE) were significant with the largest contribution of $28.70 \%$ by the environment while the interaction and genotype fractions captured $20.20 \%$ and $12.40 \%$, respectively. The percentage contribution of the main effects and GxE to total sum of squares (TSS) for traits was not consistent. The Genotype plus Genotype-by-Environment (GGE) analysis summarized $91.30 \%$ of the variation in genotype performance across environment. The cultivation environments were separated into two, with IT 95M 118 as the vertex genotype in the Ayetoro while TVU 8905 was the topmost genotype in Ago-Iwoye. The two genotypes recorded the highest grain weight per plant (GWPP) but were also the most unstable The stable genotypes IT 95M 120 and IT 86 D 716 flowered relatively late compared to others, are taller, had higher vegetative score and are low grain producers.
\end{abstract}

Key words: AMMI, drought, GGE, stability, Vigna unguiculata

\section{INTRODUCTION}

Cowpea (Vigna unguiculata L. Walp) is produced across different ecologies in Nigeria, with attendant variable performance dictated by varietal differences and weather conditions. Appreciable grain production by cowpea cultivars, particularly with minimal and erratic rainfalls a strong indicator of acceptability by farmers, particularly when such is coupled with concomitant good grain quality. Weather conditions in tropical ecologies, including that of the semi-arid zones can be quite unpredictable. The implication is serious loss in grain yield especially when cultivated variety is not adapted to such stress. Ewansiha and Osaigbovo (2016) had highlighted the potential of Cowpea as an important crop of use in farming systems, particularly the cultivation of certain cowpea varieties with dual purpose for food and fodder production and to mitigate the effect of climate change and the concomitant change in cultivation environment. A number of reports (Aremu et al., 2007; Ezeaku et al., 2012; Simion et al., 2018) have indicated the possibility of having stable cowpea genotype for cultivation in fairly related ecologies. However, some of the stable varieties are more or less average yielders by virtue of having near zero $\mathrm{PC} 1$ and also often placed around the mean yield line of the $\mathrm{G} \times \mathrm{E}$ biplots (Krisnawati and Adie, 2018; Simion et al., 2018). The existence of appreciable genotype-by-environment interaction (GxE) presupposes that genotypes would not be consistent across ecologies and as such, a genotype is rarely expected to be the best in all environments as often, best yielders appear in different environments and thereby necessitating groping of genotypes based on adaptation to specific environments (Gauch and Zobel, 1997; Yan et al., 2000; Samonte et al., 2005; Egesi et al., 2007).

Genotype-by-environment analytical tools like the Additive Main Effect and Multiplicative Interaction (AMMI) model and Genotype plus Genotype-by-Environment Interaction (GGE) have proven useful in identifying stable varieties and also those that are best in performance in different environments (Gauch and Zobel, 1997; Yan et al., 2000, 2007; Samonte et al., 2005; Yan and Tinker, 2005; Gauch, 2006). With respect to cowpea, the techniques have assisted in identifying genotypes with relatively better potential for cultivation in certain ecologies (Olayiwola et al., 2015; Sousa et al., 2018). In devolving these techniques for identifying genotypes that are stable and those

Please cite as: Nassir A.L., Olayiwola M.O., Olagunju S.O., Adewusi K.M. and Jinadu S.S. (2021). Genotype $\times$ environment analysis of cowpea grain production in the forest and derived savannah cultivation ecologies. Agro-Science, 20 (2), 20-24. DOI: https://dx.doi.org/10.4314/as.v20i2.4 
compatible with certain environments, knowledge of the underlying weather and plant variables would guide plant breeders in developing location specific cultivars for ample grain production. Krisnawathi and Adie (2018) while examining plant trait that contribute to $\mathrm{G} \times \mathrm{E}$ interaction in soybean identified early maturity as an important trait influencing most grain production in soybean. Fatokun et al. (2002) had discussed the influence of environmental indices on the reaction and performance of cowpea, particularly flowering, photoperiod sensitivity and other variables.

Different cowpea varieties are cultivated in regions with underlying variable environmental conditions. The two contrasting regions of Ogun State of Nigeria are potential cowpea cultivating regions. A guide in adoption of genotypes to be cultivated as well as information on the direction of breeding for the improvement of available genotypes would be helpful. This study consequently examined grain production of Cowpea genotypes in locations representing contrasting production environments in the Ogun State and also scrutinized the plant and environmental factors implicated in the variability.

\section{MATERIALS AND METHODS Location of Study}

This study involved evaluation of nine cowpea genotypes comprising TVU 8905, IT 84E 124, IT 84S 22464 (cultivars), IT 95M 118, IT 86D 721, IT 95M 120, IT 86D 716, IT 90K 277 2, IT 86D 719 (breeding lines) in Ago-Iwoye and Ayetoro locations in Ogun State, South-West Nigeria. The experimental sites coordinates are Lat. $3^{\circ} 2^{\prime} 47^{\prime \prime} \mathrm{N}$ and Long. $7^{\circ} 13^{\prime} 51^{\prime \prime} \mathrm{E}$ (82.906 m asl) for Ayetoro and Lat. $3^{\circ} 54^{\prime} 15^{\prime \prime} \mathrm{N}$ and Long. $6^{\circ} 57^{\prime} 3^{\prime \prime} \mathrm{E}$ $(38.100 \mathrm{~m}$ asl) for the Ago-Iwoye location. AgoIwoye is in the rain forest ecology with a bimodal rainfall pattern, of which the seasons are separated by up to four weeks of rainless days the research site has a sandy loam soil. The Ayetoro location is a derived savannah ecology with bimodal rainfall, though the seasons are not distinctly separated at times and the temperature is relatively higher than the Ago-Iwoye location. The soil of the cultivation site is identified as a loam. The rainfall and temperature data for the locations over the cultivation months are presented in Table 1 .

\section{Field Establishment}

Two cultivations were done in the Ago-Iwoye ecology between April and July (early season) and August to November (late season). In Ayetoro, only one planting was used (August to November) as the second planting failed due to abrupt cessation of rainfall. For each of the cultivations, the land was ploughed and harrowed. Seeds of the genotypes were sown as rainfall became steady to sustain germination. Each genotype occupied two- row plots separated by $60 \mathrm{~cm}$ space. There were ten plants per row. Plant spacing of $40 \mathrm{~cm}$ was maintained within the row. The genotypes were arranged in a randomized complete block (RCB) with three replications. Weeding was done once at three weeks after sowing. Fertilizer application was not done as plants did not show any sign of nutrient deficiency. Pest control was done biweekly from two weeks after sowing (WAS) with Cypermethrin at $2 \mathrm{ml} \mathrm{litre}{ }^{-1}$ of water. Benlate at $0.20 \%$ solution was sprayed at 3 and 6 WAS against diseases.

\section{Data Collection}

For each plot, ten plants, comprising five plants in the middle of each row, were used for data collection. Records were taken on days to flowering, vegetativeness, final height and grain weight per plant at harvest. Days to flowering (DF) was taken as the number of days $50 \%$ of plants in the plot flowered; final height was taken as the length of the plant from soil level to the apex of each plant. Vegetativeness, a measure of foliage density and soil coverage, was scored at anthesis using the visual score 1 for determinate, nonspreading; $3=$ indeterminate, non-spreading; $5=$ determinate, spreading; and $7=$ indeterminate spreading. Vegetativeness is of the form $7>5>3$ $>1$. Grain weight per plant (GWPP) was obtained by recovering the whole grains from each plant at harvest and obtaining the weight.

\section{Data Analysis}

Means were obtained from the sampled plants. The data from the three locations were pooled and analyzed to separate the genotype and environment (location) main effects and their interaction using the Additive Main Effect and Multiplicative Interaction (AMMI) model (Zobel et al., 1988; Gauch, 2006). The GWPP was further analyzed with the Genotype plus Genotype $\times$ Environment model (Yan et al., 2000) to generate biplots for genotype compatibility to cultivation environment and ranking of genotypes based on mean GWPP and stability. Separation of trait means for genotypes was done with the Duncan Multiple Range Test (DMRT). All analyses were done with the GenStat Version 12 Software (Payne et al., 2009).

\section{RESULTS}

The AMMI analysis for grain weight per plant (Table 2) reveals significant main effects and their interaction. The treatment accounted for $61.30 \%$ of the total sum of squares comprising the largest contribution of $28.70 \%$ by the environment while the interaction and genotype fractions captured $20.20 \%$ and $12.40 \%$ respectively. Only the first interaction component axis (IPCA 1) was significant and explained $88.70 \%$ of the $\mathrm{G} \times \mathrm{E}$ leaving a non-significant $11.3 \%$ in the residual. 
Table 3 presents the separate AMMI analysis for the main traits contributing to genotype performance and eventual grain production. The genotype $(\mathrm{G})$ and interaction (GE) effects were significant $(p<0.005)$ for days to flowering (DF), final height $(\mathrm{FH})$ and vegetativeness score (VG). The environmental effect was significant for all the traits except VG where it accounted for $1.70 \%$ of the treatment sum of squares (TRSS). The percent sum of squares captured by the G, E, and GE fractions were variable for the traits and is of the form $\mathrm{E}>\mathrm{G}>\mathrm{GE}$ for $\mathrm{DF}$; $\mathrm{GE}>\mathrm{G}>\mathrm{E}$ for $\mathrm{FH}$ and $\mathrm{G}>\mathrm{GE}>\mathrm{E}$ for $\mathrm{VG}$. The $\mathrm{GE}$ interaction was significant $(p<0.01,0.05)$ for all the traits. The first and second interaction principal component axes (IPCA1 and IPCA2) were significant $(p<0.05)$ for FH and accounted for 63.30 and 36.70 percent, respectively. Only the IPCA1 was significant for DF and captured $91.40 \%$ of the GE and also for VG where it explained $85.20 \%$ of GE.

The means of days to flowering, vegetative traits and GWPP from the nine Cowpea genotypes are shown in Table 4. Whereas IT 84E 124 recorded the least mean for days to flowering, final height and vegetativeness score, the highest mean of 83.09 $\mathrm{cm}$ and 6.11 was recorded by IT 95M 120 for final height and vegetativeness, respectively, just as the genotype also had the least GWPP. IT 95M 118 had the highest mean GWPP of $31.08 \mathrm{~g}$ though this was comparable to the other genotypes except IT 95M 120, IT 84S 22464 and IT 86D 719.

Table 1: Rainfall $(\mathrm{mm})$ and temperature $\left({ }^{\circ} \mathrm{C}\right)$ record of the cultivation months in Ago-Iwoye and Ayetoro

\begin{tabular}{|c|c|c|c|c|c|c|c|c|}
\hline \multicolumn{3}{|c|}{ Early season (Ago-Iwoye) } & \multicolumn{3}{|c|}{ Late season (Ago-Iwoye) } & \multicolumn{3}{|c|}{ Mid-late season (Ayetoro) } \\
\hline Month & $\begin{array}{c}\text { Rainfall } \\
(\mathrm{mm})\end{array}$ & $\begin{array}{c}\text { Temperature } \\
\left({ }^{0} \mathrm{C}\right)\end{array}$ & Month & $\begin{array}{c}\text { Rainfall } \\
(\mathrm{mm})\end{array}$ & $\begin{array}{c}\text { Temperature } \\
\left({ }^{0} \mathrm{C}\right)\end{array}$ & Month & $\begin{array}{c}\text { Rainfall } \\
(\mathrm{mm})\end{array}$ & $\begin{array}{c}\text { Temperature } \\
\left({ }^{0} \mathrm{C}\right)\end{array}$ \\
\hline April & 94.70 & 29.20 & August & 192.6 & 25.1 & August & 50.4 & 25.6 \\
\hline May & 173.30 & 28.10 & September & 395.7 & 26.1 & September & 135.8 & 26.9 \\
\hline June & 347.20 & 26.40 & October & 164.0 & 26.7 & October & 138.1 & 27.7 \\
\hline July & 187.20 & 25.70 & November & 16.1 & 28.4 & November & 12 & 29.4 \\
\hline
\end{tabular}

Table 2: AMMI analysis of cowpea grain production in three environments in Southern Nigeria

\begin{tabular}{lcccc}
\hline Source & df & Sum of Squares (SS) & Mean Squares (MS) & \%SS \\
\hline Total & 80 & 20568.00 & & \\
Treatment & 26 & 12602.20 & $484.70^{* *}$ & $(61.30)$ \\
Genotype (G) & 8 & 2553.80 & $319.10^{*}$ & 12.40 \\
Environment (E) & 2 & 5898.60 & $2948.80^{* *}$ & 28.70 \\
Block & 6 & 1500.40 & 249.90 & 20.20 \\
G x E & 16 & 4151.00 & $259.50^{*}$ & \\
IPCA 1 & 9 & 3680.10 & $408.90^{* *}$ & 88.70 \\
Residual & 7 & 471.10 & 67.30 & 11.30 \\
Error & 48 & 6467.60 & 134.70 & \\
\hline
\end{tabular}

Environment centred biplot for GWPP (Total - 93.31\%)

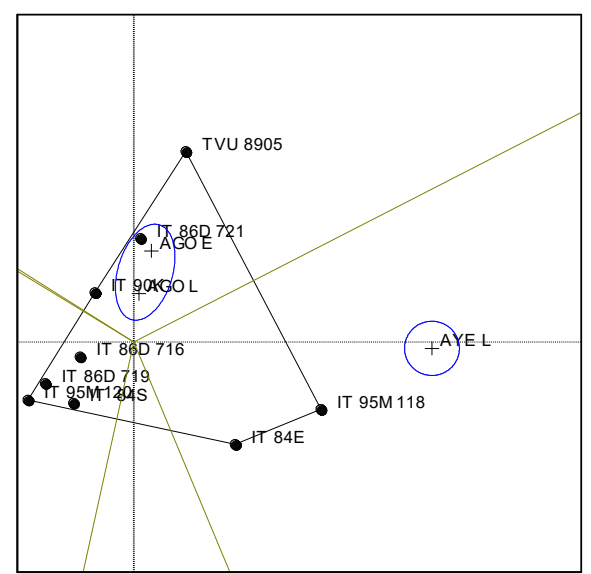

PC1 - 83.11\%

Figure 1: GGE biplot for grain weight per plant of cowpea genotypes $(\bullet)$ in three environments $(+)$

AGO E and AGO L represent Ago-Iwoye early and late season environments, respectively. AYE L represents Ayetoro late season environment.

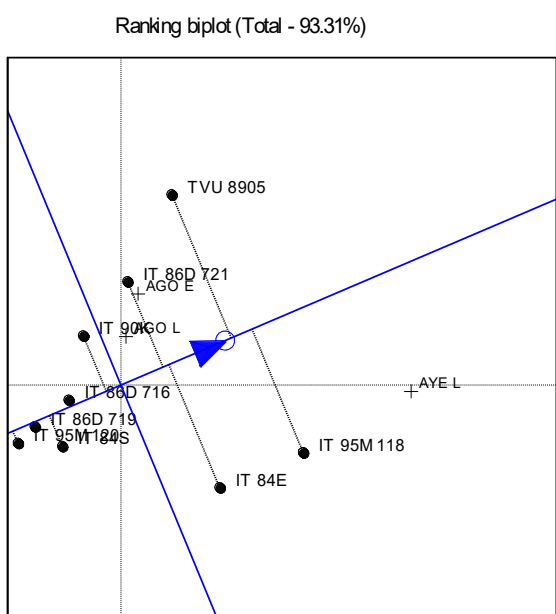

PC1 - 83.11\%

Figure 2: Mean and stability rating of cowpea genotypes $(\bullet)$ planted in three environments $(+)$.

AGO E and AGO L represent Ago-Iwoye early and late season environments, respectively. AYE L represents Ayetoro late season environment. 
Table 3: Means squares and percent sum of square estimates from AMMI analysis for cowpea traits

\begin{tabular}{llllllll}
\hline \multirow{2}{*}{ Source } & \multirow{2}{*}{$\mathrm{df}$} & \multicolumn{2}{l}{ Days to flowering } & \multicolumn{3}{c}{ Final height $(\mathrm{cm})$} & \multicolumn{3}{c}{ Vegetativeness (s) } \\
\cline { 3 - 8 } & & Mean squares & \%G+E+GE & Mean squares & \%G+E+GE & Mean squares & \%G+E+GE \\
\hline Total & 80 & 17.93 & & 659.66 & & 3.61 & \\
Treatments & 26 & $52.71^{* * *}$ & & $546.06^{* * *}$ & & $8.75^{* * *}$ & \\
Genotypes & 8 & $38.33^{* * *}$ & 22.40 & $201.76^{* * *}$ & 30.4 & $19.22^{* * *}$ & 67.60 \\
Environments & 2 & $395.42^{* * *}$ & 57.70 & $129.05^{* * *}$ & 4.9 & 1.93 & 1.70 \\
Block & 6 & 2.22 & & 18.49 & & 1.88 & \\
Interactions & 16 & $17.06^{* * *}$ & 19.90 & $215.25^{* * *}$ & 64.8 & $4.37 * * *$ & 30.70 \\
IPCA 1 & 9 & $27.72^{* *}$ & $(91.40)^{*}$ & $136.20^{* * *}$ & $(63.3)$ & $6.62^{* * *}$ & $(85.20)$ \\
IPCA 2 & 7 & 3.36 & $(8.60)$ & $79.05^{* * *}$ & $(36.7)$ & 1.48 & $(14.80)$ \\
Residuals & 0 & 0.00 & 0.00 & 0.00 & & 0.00 & \\
Error & 48 & 1.06 & & 95.11 & & 1.04 & \\
\hline
\end{tabular}

Table 4: Means of days to flowering, vegetative traits and grain weight per plant for nine cowpea genotypes

\begin{tabular}{lllll}
\hline Genotype & Days to flowering & Final height $(\mathrm{cm})$ & Vegetativeness $(\mathrm{s})$ & Grain weight per plant $(\mathrm{GWPP})(\mathrm{g})$ \\
\hline TVU 8905 & $38.22^{\mathrm{de}}$ & $78.16^{\mathrm{ab}}$ & $5.00^{\mathrm{bc}}$ & $29.70^{\mathrm{ab}}$ \\
IT 95M 118 & $37.33^{\mathrm{e}}$ & $80.70^{\mathrm{ab}}$ & $3.89^{\mathrm{de}}$ & $31.08^{\mathrm{a}}$ \\
IT 86D 721 & $39.11^{\mathrm{cd}}$ & $52.39^{\mathrm{c}}$ & $2.56^{\mathrm{fg}}$ & $26.69^{\mathrm{abc}}$ \\
IT 95M 120 & $40.78^{\mathrm{b}}$ & $83.09^{\mathrm{a}}$ & $6.11^{\mathrm{a}}$ & $14.94^{\mathrm{c}}$ \\
IT 84S 2246 4 & $39.33^{\mathrm{c}}$ & $54.06^{\mathrm{c}}$ & $3.00^{\mathrm{ef}}$ & $18.32^{\mathrm{bc}}$ \\
IT 86D 716 & $42.11^{\mathrm{a}}$ & $81.93^{\mathrm{ab}}$ & $5.67^{\mathrm{ab}}$ & $18.67^{\mathrm{abc}}$ \\
IT 84E 124 & $35.00^{\mathrm{f}}$ & $44.27^{\mathrm{c}}$ & $1.67^{\mathrm{g}}$ & $26.55^{\mathrm{abc}}$ \\
IT 90K 277 2 & $39.89^{\mathrm{bc}}$ & $69.18^{\mathrm{b}}$ & $3.89^{\mathrm{de}}$ & $21.54^{\mathrm{abc}}$ \\
IT 86D 719 & $40.00^{\mathrm{bc}}$ & $78.81^{\mathrm{ab}}$ & $4.56^{\mathrm{cd}}$ & $16.66^{\mathrm{c}}$ \\
Mean & 39.09 & 69.18 & 4.04 & 22.68 \\
\hline
\end{tabular}

The GGE biplot for GWPP over the environments are displayed in Figure 1. The analysis captured $91.30 \%$ of the variation in genotype performance across environment. The genotypes were separated into three sectors with the environments appearing in only two. IT 95M 118 was the vertex genotype in the Ayetoro cultivation but was also grouped with IT 84E 124. The Ago-Iwoye early and late seasons cultivation were grouped with TVU 8905 the topmost genotype in the sector which also include IT 86D 721 and IT 90K 2772 . The ranking of genotypes for grain yield and stability is shown in Figure 2. Genotypes with above overall mean yield were also the most unstable. TVU 8905 was the most unstable followed by IT 95 M 118, IT 84E 124 and IT 90K 2772 in that order. The stable genotypes, particularly IT 95M 120 and IT 86 D 716 are low grain producers. These two stable genotypes flowered relatively late compared to others, are taller and also have higher vegetative score.

\section{DISCUSSION}

Significant genotype and environment effects are to be expected where genotypes and the environment accounted for appreciable phenotypic variation as to give differential plant output, just as it was in this study. The significant $\mathrm{G} \times \mathrm{E}$ interaction further explains the existing variability among the genotypes and underpins their inconsistent performance across the testing environments. However, the genotype-environment interaction was less complex since only the IPCA 1 was significant; hence the interaction can largely be predicted (Yan and Hunt, 1998; Samonte et al., 2005) as the environment improves or declines with respect to the main environmental determinant, obviously moisture and temperature in this regard. The higher percentage of the variations explained by the GGE analysis indicates that the method is more versatile in capturing the differences in the performance of the cowpea genotypes over the environments. The AMMI tool can be used to establish $\mathrm{G} \times \mathrm{E}$ interaction while the GGE method can serve to explain in more details genotypic compatibility to the cultivation environments.

The differences in the pattern of the treatment variation explained by the main effects and interaction for the traits point to the complexity in and the influence of cultivation environment on genotype performance. Environment, for instance, play a major role in influencing early flowering even though the genotypic control is also significant. Environment however appeared to play less prominent role in expression of height and vegetativeness even though the influence of genotype and GE was reversed for the traits.

There is an indication that earliness, short stature and low vegetativeness may not necessarily impair grain production as observed with IT 84E 124. Conversely, high vegetativeness may not translate into deposit of large amount of photosynthates into the grains, which are the terminal sink organ in cowpea. It would appear that some balance of days to flowering, plant height and vegetativeness, as observed with IT 85 M 118 and TVU 8905 would translate into improved grain production.

The Ago-Iwoye early and late season environments are similar in the conditions provided for cowpea grain production, but different from the Ayetoro environment. Following rainfall pattern, the total rainfall in the two months that coincided with the peak of vegetative growth and flowering was relatively high for Ago-Iwoye (May and June for early; September and October for late) compared to the Ayetoro environment (September and October). TVU 8905 had moderate vegetativeness 
and was best for grain production in the Ago-Iwoye environment. The other genotypes in the sector (IT 86D 721 and IT 90K 277 2) were also similar to TVU 8905 in respect of vegetativeness but had relatively low GWPP. This is instructive in developing genotypes for Ago-Iwoye and such high rainfall tropical locations. IT 95M 118 gave the best GWPP in Ayetoro and also had the overall highest GWPP. IT 84E 124, which shared the sector with IT 95M 118, would also be good for cultivation in the environment. The two genotypes had the least number of days to flowering and low vegetativeness score. By implication, early flowering genotypes with low vegetativeness would be best for low moisture but high temperature environment which Ayetoro typifies.

The stability rating and grain production capability of genotypes suggest the need to develop cowpea genotypes for even seemingly contiguous locations, especially when the environmental factors have changed, reasonably. In doing this, Ezeaku et al. (2012) had stressed the importance of relating genotypic performance with differences in vegetative and reproductive traits. For this study, Ayetoro is aderived savannah ecology while AgoIwoye is located in the rain forest. The two locations are roughly $150 \mathrm{~km}$ apart and as observed elicited differences in varietal response and compatibility. It also appeared that late maturing and highly vegetative genotypes, though stable but produced poor grain yield and would thereby not be good for cultivation in the locations.

\section{CONCLUSION}

Nine cowpea genotypes were cultivated in AgoIwoye and Ayetoro locations with some differences in temperature and rainfall. The Additive Main Effect and Multiplicative Interaction (AMMI) model captured $61.30 \%$ of the variation in genotype performance and established the presence of genotype $\mathrm{x}$ environment interaction for the traits. The percentage contribution of the main effects and $\mathrm{G} \times \mathrm{E}$ to TSS was however not consistent for the traits. Genotype plus Genotype-by-Environment (GGE) analysis, which captured both genotypic effect and $\mathrm{G} \times \mathrm{E}$ explained $91.30 \%$ of the variation thereby making it superior analytical tool in this study. The GGE classified the cultivation environments into two, with IT 95M 118 as the vertex genotype in the Ayetoro for GWPP while TVU 8905 was best genotype in Ago-Iwoye. The two genotypes had the highest GWPP but were also the most unstable. The most stable genotypes were IT 95M 120 and IT 86 D 716 but also produced the least GWPP, flowered relatively late compared to others and recorded higher vegetative score. A compromise between early flowering and vegetativeness may have to be struck in developing stable but high yielding genotype for and across the high and low moisture locations.

\section{REFERENCES}

Aremu C.O., Ariyo O.J. and Adewale B.D. (2007). Assessments of selection techniques in genotype-by-environment interaction in cowpea (Vigna unguiculata (L.) Walp). Afr. J. of Agric. Res., 2, 352-355

Egesi C.N., Ilona P., Ogbe F.O., Akoroda M. and Dixon A. (2007). Genetic variation and genotype $\mathrm{x}$ environment interaction for yield and other agronomic traits in cassava in Nigeria. Agron. J., 99, 1137-1142

Ewansiha S.U. and Osaigbovo A.U. (2016). Cowpea for a changing environment in the rainforest of SouthSouth Nigeria. Agro-Science, 15 (1), 2328http://dx.doi.org/10.4314/as.v1511.5

Ezeaku I.E., Mbah B.N. and Baiyeri K.P. (2012). Multilocation evaluation of yield and yield components of grain cowpea (Vigna unguiculata (L.) Walp.) grown in Southeastern Nigeria. Agro-Science, 11 (3), 27-37. http://dx.doi.org/10.4314/as.v11i3.4

Fatokun C.A., Tarawali S.A., Singh B.B., Kormawa P.M. and Tamò M. (2002). Challenges and opportunities for enhancing sustainable cowpea production. Proc. of the III World Cowpea Conf. held at the International Institute of Tropical Agriculture (IITA), Ibadan, Nigeria, 4-8 Sep. 2000. IITA, Ibadan, Nigeria

Gauch H.G. (2006). Statistical analysis of yield trials by AMMI and GGE. Crop Sci., 46, (4), 1488-1500 https://doi.org/10.2135/cropsci2005.07-0193

Gauch H.G. Jr. and Zobel R.W. (1997). Identifying mega-environments and targeting genotypes. Crop Sci., 37, 311-326

Krisnawati A. and Adie M.M. (2018). GGE Biplot analysis of multi-environment yield trials in soybean promising lines. Ilmu Pertanian (Agric. Sc.), 3 (2), 72-81

Olayiwola M.O., Soremi P.A.S. and Okeleye K.A. (2015). Evaluation of some cowpea (Vigna unguiculata L. Walp.) genotypes for stability of performance over 4 years. Current Res. in Agric. Sci., 2 (1), 22-30

Payne R.W., Harding S.A., Murray D.A. et al. (2009). GenStat for Windows (12 ed.) Introduction. VSN Int. Hemel Hemstead, UK: VSN International

Samonte S.O.P.B., Wilson L.T., McClung A.M. and Medley J.C. (2005). Targeting cultivars onto Rice growing environments using AMMI and SREG GGE Biplot analyses. Crop Sci., 45, 2414-2424

Simion T., Mohammed W. and Amsal B. (2018). Genotype by environment interaction and stability analysis of cowpea (Vigna unguiculata (L.) Walp) genotypes for yield in Ethiopia. J. of Plant Breed. and Crop Sci., 10 (9), 249-257

Sousa M.B.E., Damasceno-Silva K.J., Rocha M. et al. (2018). Genotype by environment interaction in cowpe lines using GGE Biplot method. Rev. Caatinga, Mossoró., 31, (1), 64-71

Yan W. and Hunt L.A. (1998). Genotype by environment interaction and crop yield. Plant Breed. Rev., 16, 135-178

Yan W., Hunt, L.A., Sheng Q. and Szlavnics Z. (2000). Cultivar evaluation and mega-environment investigation based on the GGE Biplot. Crop Sci., 40, 597-605

Yan W. and Tinker N.A. (2005). An integrated system of biplot analysis for displaying, interpreting, and exploring genotype by environment interactions. Crop Sci., 45,1004-1016

Yan W., Kang M.S., Ma B., Woods S. and Cornelius P.L. (2007). GGE biplot vs. AMMI analysis of genotypeby-environment data. Crop Sci., 47, (2), 643-655

Zobel R.W., Wright M.J. and Gauch H.G. Jr. (1988). Statistical analysis of a yield trial. Agron. J., 80, 388-393 